$16^{\text {th }}$ International Conference on

AEROSPACE SCIENCES \& AVIATION TECHNOLOGY,

ASAT - 16 - May 26 - 28, 2015, E-Mail: asat@ mtc.edu.eg Military Technical College, Kobry Elkobbah, Cairo, Egypt

Tel : +(202) 24025292 - 24036138, Fax: +(202) 22621908

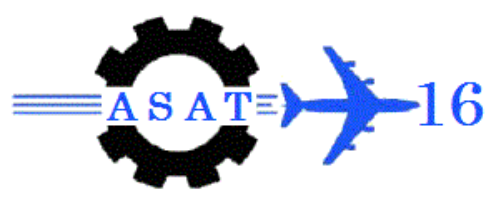

\title{
Design of Fractional Order PID Controller for SMIB Power System with UPFC Tuned by Multi-Objectives Genetic Algorithm
}

\author{
S.S. Mohamed ${ }^{1}$
}

Ahmed Elbioumey Mansour ${ }^{2}$ and

\begin{abstract}
:
This paper presents the design steps and carries a comparative study between three Proportional-Integral-Derivative (PID) controllers. The gains of the first PID are optimized using Genetic Algorithm (GA), named pid. In the second controller, the parameters setting of the Fractional Order PID controller are found using GA, named fopid. The pid and fopid controllers employ cost function that represents the Integral Squared Errors (ISE) to evaluate the controller gains. In the third controller, Multi-Objectives Genetic Algorithm (MOGA) is reformulated to design Fractional Order PID Controller named Mfopid. The proposed controllers have been applied to a Unified Power Flow Controller (UPFC) to control generator terminals voltage and better damping of Low Frequency Oscillation in SingleMachine Infinite-Bus (SMIB) power system. In additional, power system stabilizer (PSS) control parameters are tuned with pid based ISE using GA to increase damping of power system Oscillations. The PSS control parameters remain constant during the design procedure of the two proposed fopid and Mfopid controllers. To show the effectiveness of the designed controllers, the obtained results are compared through sever disturbances with different operating conditions. Results evaluation show that the proposed Mfopid controller achieves good performance and is superior to the other controllers
\end{abstract}

Keywords: SMIB, UPFC, PID, fractional order $\mathrm{PI}^{\lambda} \mathrm{D}^{\mu}$ controller, multi-objectives genetic algorithm FOPID.

1- Egyptian Company Electricity Transmission, The Ministry of Electricity, Cairo, Egypt. eng_sarah29685@hotmail.com.

2- Electrical Power \& Machines Department, Faculty of Engineering -Al-azhar University, Cairo, Egypt. dr.ahmed.mansour@gmail.com.

3- Electrical Power \& Machines Department, Faculty of Engineering - Helwan University of Helwan, Cairo, Egypt. ghanymohamed@ieee.org. 


\section{Introduction:}

The Flexible AC Transmission Systems (FACTS) based on power electronics offer an opportunity to enhance controllability, stability and power transfer capability of AC transmission systems. The Unified Power Flow Controller (UPFC), which is the most versatile FACTS device, has the capabilities of controlling power flow in the transmission line, improving the transient stability, mitigating system oscillation and providing voltage support [1-3]. The UPFC damping controller design can be found in [4-6]. The supplementary controller can be applied to the series inverter through the modulation of the power reference signal or to the shunt inverter through the modulation index of the reference voltage signal.

The proportional-integral-derivative (PID) controller is one of the most widely used controllers in industry and by far the most dominating form of feedback in use today. In practice systems use simple PID controller for control of UPFC. Also, in the field of automatic control, the fractional order PID (FOPID) controllers which are the generalization of classical integer order controllers would lead to more precise and robust control performances [7-10]. Although it is reasonably true that the fractional order models require the FOPID controllers to achieve the best performance, in most cases the researchers consider the fractional order controllers applied to regular linear or non-linear dynamics to enhance the system control performances [11, 12].

Even though the wide popularity of the PID and recently FOPID control schemes in the industrial world, the parameters of these controllers are normally fixed and usually tuned manually or using trial-and error approach or by conventional control methods $[13,14]$. Therefore, it is incapable of obtaining good dynamical performance to capture all design objectives and specifications for a wide range of operating conditions and disturbances. Attempts to incur the above mentioned limitations is offered in [13,14], using Ziegler-Nichols (ZN) method to tune the PID and FOPID.

Recently, the social inspired optimization algorithms become a successful alternative as a tuning method to adapt the PID and FOPID controllers. These algorithms are adopted by many researchers for tuning PID controller in its intelligent forms [15-17]. One such approach is Genetic Algorithm (GA) Optimization which has been applied to control UPFC in electric power systems [18-20].

This paper presents the design steps and a comparative study between three PID controllers. The main task of each of the controllers is to control the generator terminal voltage and PSS based UPFC for damping low frequency oscillations in power system. The design procedures are based on GA optimization method to tune the proposed controller parameters. The optimized PID and FOPID controllers which have been designed are abbreviated to pid, fopid and Mfopid, respectively. The gains setting of the pid and fopid controllers are optimized based on integral square error (ISE). The parameters of the PSS are optimized with the pid controller and remain constant with other controllers. The third Mfopid controller is tuned using Multi-Objectives Genetic Algorithm (MOGA) in MATLAB toolbox. To show the effectiveness of each controller and to carry a comparative study, several cases under variation of system disturbances with a wide range of operating conditions are performed. The results of simulation show that the effect of the Mfopid controller is better and good performance than that of the fopid and pid controllers under different disturbances with a wide range of operating conditions.

\section{Fractional-Order Proportional-Integral-Derivative Controller}

PID controllers belong to dominant industrial controllers and therefore are topics of steady effort for improvements of their quality and robustness. One of the possibilities to improve 
PID controllers is to use fractional-order controllers with non-integer derivation and integration parts.

Controlling industrial plants requires satisfaction of wide range of specification. So, wide ranges of techniques are needed. Mostly for industrial applications, integer order controllers are used for controlling purpose. Now day's fractional order (FOPID) controller is used for industrial application to improve the system control performances. The most common form of a fractional order PID controller FOPID is the $\mathrm{PI}^{\lambda} \mathrm{D}^{\mu}$ controller. It allows us to adjust derivative $(\lambda)$ and integral $(\mu)$ order in addition to the proportional, integral and derivative constants where the values of $\lambda$ and $\mu$ lie between 0 and 1 . This gives extra freedom to operator in terms of two extra knobs i.e.

- Order of differentiation

- Order of integration

This also provides more flexibility and opportunity to better adjust the dynamical properties of the control system. The fractional order controller revels good robustness. The robustness of fractional controller gets more highlighted in presence of a non-linear actuator. Fig. 1 shows the block diagram of a FOPID controller system [13].

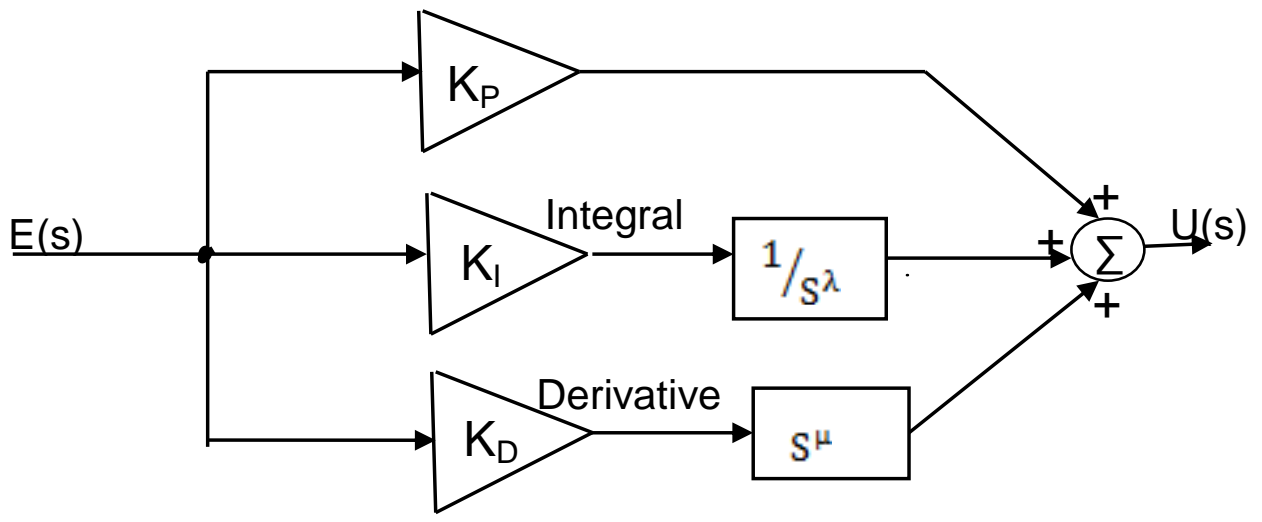

Fig.1 Block diagram of FOPID

The transfer function for FOPID controller is given by

$$
\mathrm{G}_{\mathrm{c}}(\mathrm{s})=\frac{\mathrm{U}(\mathrm{s})}{\mathrm{E}(\mathrm{s})}=\mathrm{k}_{\mathrm{p}}+\mathrm{k}_{\mathrm{I}} \frac{1}{\mathrm{~s}^{\lambda}}+\mathrm{k}_{\mathrm{D}} \mathrm{s}^{\mu}, \quad(\lambda, \mu>0)
$$

Where: $\mathrm{G}_{\mathrm{c}}(\mathrm{s})$ is the transfer function of controller, $\mathrm{E}(\mathrm{s})$ is the error, $\mathrm{U}(\mathrm{s})$ is the output.

Taking $\lambda=1$ and $\delta=1$, we obtain a classical PID controller. If $\lambda=0$ we obtain a PD $^{\mu}$ controller and If $\mu=0$ a PI ${ }^{\lambda}$ controller can be recovered. All these types of controllers are the particular cases of the fractional FOPID $\left(\mathrm{PI}^{\lambda} \mathrm{D}^{\mu}\right)$ controller [13].

It can be expected that FOPID controller may enhance the systems control performance due to more tuning knobs introduced. One of the most important advantages of the fractional order $\mathrm{PI}^{\lambda} \mathrm{D}^{\mu}$ controller is the possible better control of fractional order dynamical systems. Another advantages lies in the fact that the FOPID controllers are less sensitive to changes of parameters of a controlled system. This is due to the two extra degrees of freedom to better adjust the dynamical properties of a fractional order control system.

The Ninteger toolbox is used to simulate and analyze the FOPID controllers easily via its function nipid [21].

\section{Fractional order PID Controller tuning}


FOPID control is a useful control strategy, since it provides five parameters $\left(\mathrm{K}_{\mathrm{P}}, \mathrm{K}_{\mathrm{I}}, \mathrm{K}_{\mathrm{D}}, \lambda\right.$ and $\mu$ ) to be tuned as opposed to the three available $\left(K_{P}, K_{I}\right.$ and $\left.K_{D}\right)$ in ordinary PID control. The FOPID transfer function in series with the plant transfer function is shown in Fig.2.

Where: $\mathrm{G}(\mathrm{s})$ is the process, $\mathrm{R}(\mathrm{s})$ is the reference input, $\mathrm{D}(\mathrm{s})$ is the disturbance and $\mathrm{Y}(\mathrm{s})$ is the output.

Fig. 2 Closed loop control system

There are several quality control criterions to evaluate the controller performance and to design the controller parameters by optimization, which fulfill desired design specifications. In this work Fractional Order PID controllers are tuned based on:

\subsection{Design Steps of fopid and pid Controller Using Minimized function:}

To find the five unknown parameters $\left(K_{P}, K_{I}, K_{D}, \lambda\right.$ and $\left.\mu\right)$ of fopid and the three gains $\left(K_{P}\right.$, $\mathrm{K}_{\mathrm{I}}$ and $\mathrm{K}_{\mathrm{D}}$ ) of pid as shown in equation 1, the design procedure can be summarized as follows:

Step 1: Insert the fopid or pid transfer function in series with the plant transfer function as shown in Fig.2.

Step 2: Calculate the performance criteria ISE to tune the controller parameters given by equation 2 .

$$
J=\int_{0}^{\infty}\left[\Delta \mathrm{V}_{\mathrm{t}}(\mathrm{t})\right]^{2} \mathrm{dt}
$$

Step 3: Choose an initial random parameters of the controller gains.

Step 4: Use optimization GA toolbox for pid and GA with Ninteger toolboxs for fopid

Step 5: Minimize ISE index iteratively to find optimal the set of parameters of the pid or fopid controller.

Step 6: Terminate the algorithm if the value of the objective function does not change appreciably over some successive iteration.

Step 7: Find the optimal controller parameters values and simulate the controlled system to validate the proposed controller.

\subsection{Design Steps of FOPID Controller Using Multi-objective Optimization (Mfopid):}

The design procedure of Mfopid controller can be summarized as follows:

Step 1: let a set of upper and lower bounds on the design variables $\left(K_{P}, K_{I}, K_{D}, \lambda\right.$ and $\left.\mu\right)$,

Step 2: Run the optimization Multi-objective GA with Ninteger toolboxes of Matlab,

Step 3: Calculate the controller parameters through the following minimization tuning method,

a) Let $0<\lambda<1$ to eliminate steady state error as fractional integrator of order $\mathrm{k}+\lambda$ is properly implemented for steady state error cancellation as efficient as an integer order integrator of order $\mathrm{k}+1$.

b) Maximize the gain margin $\mathrm{G}_{\mathrm{m}}$ to grantee stability as gain cross over frequency $\omega_{\mathrm{cg}}$ will have specified value using the following equation.

$$
\mathrm{G}_{\mathrm{m}}=20 \log \left(\mathrm{G}_{\mathrm{c}}\left(\omega_{\mathrm{cg}}\right) \mathrm{G}\left(\omega_{\mathrm{cg}}\right)\right)=0 \mathrm{db}
$$


c) Maximize phase margin $\varphi_{m}$ through the following equation to let the compensated system more stable.

$$
-\pi+\varphi_{\mathrm{m}}=\arg \left(\mathrm{G}_{\mathrm{c}}\left(\omega_{\mathrm{cg}}\right) \mathrm{G}\left(\omega_{\mathrm{cg}}\right)\right)
$$

d) Let the closed loop transfer function have a small magnitude at specified frequency magnitude $\omega_{\mathrm{h}}$ to be less than specified gain $\mathrm{H}$ at the next equation to reject the highfrequency noise.

$$
\left|\frac{\mathrm{G}_{\mathrm{C}}\left(\omega_{\mathrm{h}}\right) \mathrm{G}\left(\omega_{\mathrm{h}}\right)}{1+\mathrm{G}_{\mathrm{C}}\left(\omega_{\mathrm{h}}\right) \mathrm{G}\left(\omega_{\mathrm{h}}\right)}\right| \leq \mathrm{H}
$$

e) To be robust in face of gain variations of the plant, the phase of the open-loop transfer function must be (at least roughly) constant around the gain-crossover frequency

$$
\left(\frac{d \arg \left(G_{c}(j \omega) G(j \omega)\right.}{d \omega}\right)_{\omega=\omega_{c g}}=0
$$

f) To reject output disturbances and closely follow references, the sensitivity function must have a small magnitude at low frequencies; thus it is required that at some specified frequency $\omega_{\mathrm{S}}$, its magnitude be less than some specified gain $\mathrm{N}$ :

$$
\left|\frac{1}{1+G_{C}\left(\omega_{S}\right) G\left(\omega_{S}\right)}\right| \leq N
$$

A set of five of these six specifications can be met by the closed-loop system, since the fractional controller $\mathrm{G}_{\mathrm{C}}(\mathrm{s})$ has five parameters to tune. In our case, the specifications considered are those in equations (3), (4), (5), (6) and (7), ensuring a robust performance of the controlled system to gain changes and noise and a relative stability and bandwidth specifications. The condition of no steady-state error is fulfilled just with the introduction of the fractional integrator properly implemented, as commented before.

Step 4: Add ISE as an additional index to find optimal parameters set of the Mfopid controller.

Step 5: Run the optimization toolbox of Matlab to reach out the better solution with the minimum error using Multi-objective Optimization Genetic Algorithm (MOGA).

Step 6: Stop if the value of the objective function does not change appreciably over some successive iteration.

Step 7: Get the result of the tuning controller parameters.

Step 8: Run the closed loop control system and plot the output responses.

\subsection{Genetic Algorithm}

This section provides a brief description about genetic algorithm (GA) [18-19] and its application in the minimization of $\mathbf{J}$. Genetic algorithm is a stochastic optimization process inspired by natural evolution. During the initialization phase, a random population of solution vectors with uniform distribution is created over the whole solution domain. The population is encoded as a double vector. 
Fitness evaluation: Since the purpose of using genetic algorithm is to determine a reduce order model with minimizing objective function $\mathbf{J}$ from the search space.

Reproduction: Individual strings are copied based on the fitness and sent to the mating pool. There production operation is implemented using roulette wheel arrangement.

Crossover: During crossover operation, two strings selected at random from the mating pool undergo crossover with a certain probability at a randomly selected crossover point to generate two new strings.

Mutation: Depending on whether a randomly generated number is larger than a predefined mutation probability or not, each bit in the string obtained after crossover is altered (changing 0 to 1 and 1 to 0 ).

In each generation, the fittest member's fitness function value is compared with that of the previous fittest one. If a very insignificant improvement is seen for some successive generations then the algorithm is stopped, otherwise all the operations described above are carried out till a model is obtained with a desired objective function $\mathbf{J}$ (equation 2).

In the fractional controller case, the specification in each unit transfer function equation is taken as the main function to minimize, and the rest of specifications $(3, \ldots, 7)$ are taken as constrains for the minimization for each unit, all of them subjected to the optimization parameters $\left(K_{P}, K_{I}, K_{D}, \lambda\right.$ and $\left.\mu\right)$ defined using multi-objectives genetic algorithm [10].

\section{Dynamic Modeling of Power System with UPFC}

Fig.3 shows a single-machine-infinite-bus (SMIB) power system installed with UPFC. The UPFC consists of a shunt and a series transformer, which are connected via two voltage source converters with a common DC-capacitor and $\mathrm{m}_{\mathrm{E}}, \mathrm{m}_{\mathrm{B}}, \delta_{\mathrm{E}}$ and $\delta_{\mathrm{B}}$ are the amplitude modulation ratio and phase angle of the reference voltage of each voltage source converter respectively. These values are the input control signals of the UPFC.

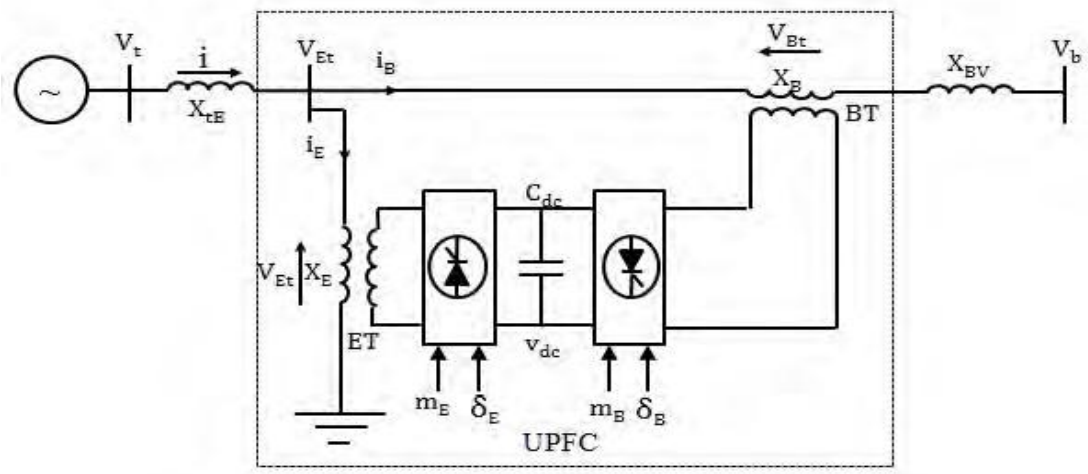

Fig. 3 SMIB power system installed with UPFC

A linearized model of the power system is used in studying dynamic studies of power system. In order to consider the effect of UPFC, the dynamic model of the UPFC is employed. The Dynamic model of the SMIB with UPFC can be represented as $[3,4]$ : 


$$
\left[\begin{array}{c}
\dot{\Delta \delta} \\
\Delta \dot{\omega} \\
\Delta \dot{\mathrm{E}}_{\mathrm{q}}^{\prime} \\
\Delta \dot{\mathrm{E}}_{\mathrm{fd}} \\
\Delta \dot{\mathrm{V}}_{\mathrm{dc}}^{\prime}
\end{array}\right]=
$$$$
\left[\begin{array}{ccccc}
0 & \omega_{\mathrm{B}} & 0 & 0 & 0 \\
\frac{-\mathrm{K}_{1}}{2 \mathrm{H}} & \frac{-\mathrm{D}}{2 \mathrm{H}} & \frac{-\mathrm{K}_{2}}{2 \mathrm{H}} & 0 & -\frac{\mathrm{K}_{\mathrm{pdc}}}{2 \mathrm{H}} \\
\frac{-\mathrm{K}_{4}}{\mathrm{~T}_{\mathrm{do}}^{\prime}} & 0 & \frac{-\mathrm{K}_{3}}{T_{\mathrm{do}}^{\prime}} & \frac{1}{\mathrm{~T}_{\mathrm{do}}} & -\frac{\mathrm{K}_{\mathrm{qdc}}}{\mathrm{T}_{\mathrm{do}}} \\
\frac{-\mathrm{K}_{\mathrm{A}} \mathrm{K}_{5}}{\mathrm{~T}_{\mathrm{A}}} & 0 & \frac{-\mathrm{K}_{\mathrm{A}} \mathrm{K}_{6}}{\mathrm{~T}_{\mathrm{A}}} & \frac{-1}{\mathrm{~T}_{\mathrm{A}}} & -\frac{\mathrm{K}_{\mathrm{A}} \mathrm{K}_{\mathrm{Vdc}}}{\mathrm{T}_{\mathrm{A}}} \\
\mathrm{K}_{7} & 0 & \mathrm{~K}_{8} & 0 & -\mathrm{K}_{9}
\end{array}\right]\left[\begin{array}{c}
\Delta \delta \\
\Delta \omega \\
\Delta \mathrm{E}_{\mathrm{q}}^{\prime} \\
\Delta \mathrm{E}_{\mathrm{fd}} \\
\Delta \mathrm{V}_{\mathrm{dc}}
\end{array}\right]+
$$

$$
\left[\begin{array}{cccc}
0 & 0 & 0 & 0 \\
\frac{-\mathrm{K}_{\mathrm{PE}}}{2 \mathrm{H}} & \frac{-\mathrm{K}_{\mathrm{P} \delta_{\mathrm{E}}}}{2 \mathrm{H}} & \frac{-\mathrm{K}_{\mathrm{PB}}}{2 \mathrm{H}} & \frac{-\mathrm{K}_{\mathrm{P} \delta_{\mathrm{B}}}}{2 \mathrm{H}} \\
\frac{-\mathrm{K}_{\mathrm{q}}}{\mathrm{T}_{\mathrm{do}}^{\prime}} & \frac{-\mathrm{K}_{\mathrm{q} \delta_{\mathrm{E}}}}{\mathrm{T}_{\mathrm{do}}^{\prime}} & \frac{-\mathrm{K}_{\mathrm{q}}}{\mathrm{T}_{\mathrm{do}}} & \frac{-\mathrm{K}_{\mathrm{q} \delta_{\mathrm{B}}}}{\mathrm{T}_{\mathrm{do}}^{\prime}} \\
\frac{-\mathrm{K}_{\mathrm{A}} \mathrm{K}_{\mathrm{VE}}}{\mathrm{T}_{\mathrm{A}}} & \frac{-\mathrm{K}_{\mathrm{A}} \mathrm{K}_{\mathrm{V}_{\mathrm{E}}}}{\mathrm{T}_{\mathrm{A}}} & \frac{-\mathrm{K}_{\mathrm{A}} \mathrm{K}_{\mathrm{VB}}}{\mathrm{T}_{\mathrm{A}}} & \frac{-\mathrm{K}_{\mathrm{A}} \mathrm{K}_{\mathrm{V} \delta_{\mathrm{B}}}}{\mathrm{T}_{\mathrm{A}}} \\
\mathrm{K}_{\mathrm{CE}} & \mathrm{K}_{\mathrm{C} \delta_{\mathrm{E}}} & \mathrm{K}_{\mathrm{CB}} & \mathrm{K}_{\mathrm{C} \delta_{\mathrm{EB}}}
\end{array}\right]\left[\begin{array}{c}
\Delta \mathrm{m}_{\mathrm{E}} \\
\Delta \delta_{\mathrm{E}} \\
\Delta \mathrm{m}_{\mathrm{B}} \\
\Delta \delta_{\mathrm{B}}
\end{array}\right]
$$

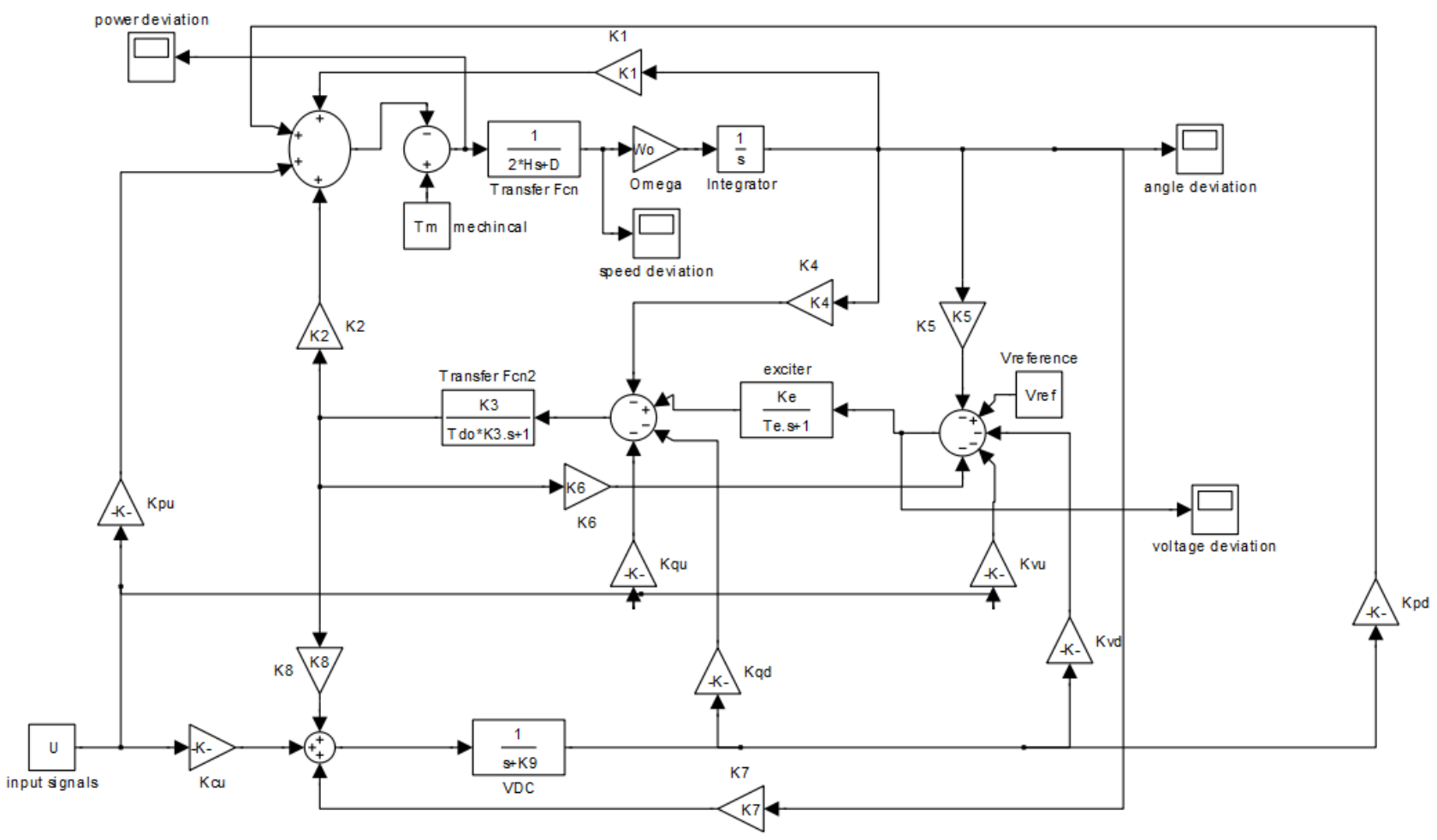

Fig.4 Transfer function model of the SMIB system including UPFC.

Fig. 4 shows the transfer function model of the SMIB system including UPFC, the $\mathrm{K}$ constants depend on the system parameters and the initial operating conditions are given in Appendix. In this study, UPFC has two internal controllers which are Power system oscillation-damping controller and bus voltage controller. Fig.5 shows the structure of the generator terminals voltage controller. $\mathrm{m}_{\mathrm{B}}$ is modulated in order to generator bus voltage controller design; also the bus voltage deviation $\Delta \mathrm{V}_{\mathrm{t}}$ is considered as the input to the PID controller. The generator terminals voltage controller regulates the voltage of generator terminals during post fault in system. Also a stabilizer controller is provided to improve damping of power system oscillations and stability enhancement. $\mathrm{m}_{\mathrm{B}}$ is modulated in order to stabilize controller design; also the speed deviation $\Delta \omega$ is considered as the input to the stabilizer controllers. The transfer function model of the stabilizer controller is shown in Fig. 6. 


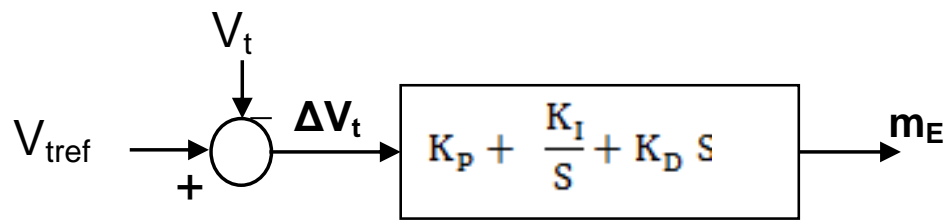

Fig. 5 Generator terminals voltage controller (PID controller)

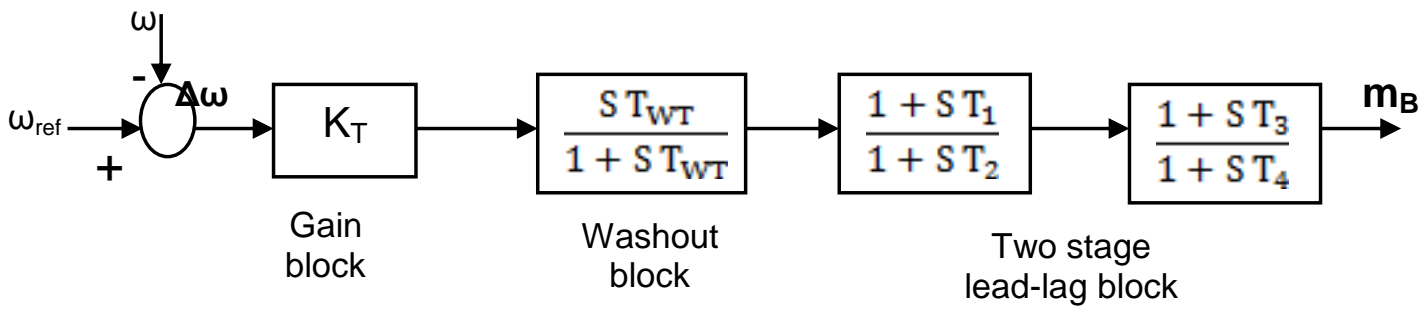

Fig. 6 Structure of the UPFC-based damping controller (PSS controller)

The structure of stabilizer controller consists of gain, signal washout and a lead-lag compensator block. The optimizing parameters to damp UPFC oscillations are obtained based (ISE) using GA. The PSS control parameters remain constant during the design procedure of the three controllers proposed (pid, fopid and Mfopid) and the damping controller is designed as Equation (9).

$$
\text { Damping controller }=34.808 \frac{10 \mathrm{~S}}{10 \mathrm{~S}+1} \frac{0.051 \mathrm{~S}+1}{0.05 \mathrm{~S}+1} \frac{0.228 \mathrm{~S}+1}{0.05 \mathrm{~S}+1}
$$

\section{Simulation Results}

To assess the effectiveness of the pid, fopid, Mfopid controllers to control SMIB power system with UPFC various disturbances and operating condition variations are considered. The results obtained when using the pid, fopid and Mfopid controllers are shown in Fig. 7. The response with pid controller is shown in dashed lines (with legend "pid") and the response with fopid controller is shown red solid lines (with legend "fopid"). The response with Mfopid controller is shown in solid lines (with legend "Mfopid"). The optimal parameters of the pid and fopid are optimized using ISE. Also the optimization parameters of Mfopid are obtained with the minimum error using MOGA. The digital simulation results are obtained using MATLAB Platform. The constants $\mathbf{K}=[\mathrm{K} 1, \ldots, \mathrm{K} 6]$ of the power system in the normal, heavy and light loads are given in Table 1.

Table 1 Constants K values

\begin{tabular}{|c|c|c|c|}
\hline $\mathbf{K}$ & $\begin{array}{c}\text { Normal condition } \\
\mathbf{P = 0 . 8}, \mathbf{Q = 0 . 2}, \mathbf{V}_{\mathbf{t}}=\mathbf{1 . 0}\end{array}$ & $\begin{array}{c}\text { Light condition } \\
\mathbf{P = 0 . 8}, \mathbf{Q}=\mathbf{0 . 1 7}, \mathbf{V}_{\mathbf{t}}=\mathbf{1 . 2}\end{array}$ & $\begin{array}{c}\text { Heavy condition } \\
\mathbf{P}=\mathbf{1 . 3}, \mathbf{Q}=\mathbf{0 . 2}, \mathbf{V}_{\mathbf{t}}=\mathbf{0 . 9}\end{array}$ \\
\hline $\mathrm{K}_{1}$ & 0.5661 & 0.6234 & 1.4076 \\
\hline $\mathrm{K}_{2}$ & 0.1712 & 1.2813 & 1.1984 \\
\hline $\mathrm{K}_{3}$ & 2.4583 & 0.3071 & 0.3071 \\
\hline $\mathrm{K}_{4}$ & 0.4198 & 1.7123 & 1.6461 \\
\hline $\mathrm{K}_{5}$ & -0.1513 & -0.2091 & 1.0742 \\
\hline $\mathrm{K}_{6}$ & 0.3516 & 0.4565 & 0.5488 \\
\hline
\end{tabular}




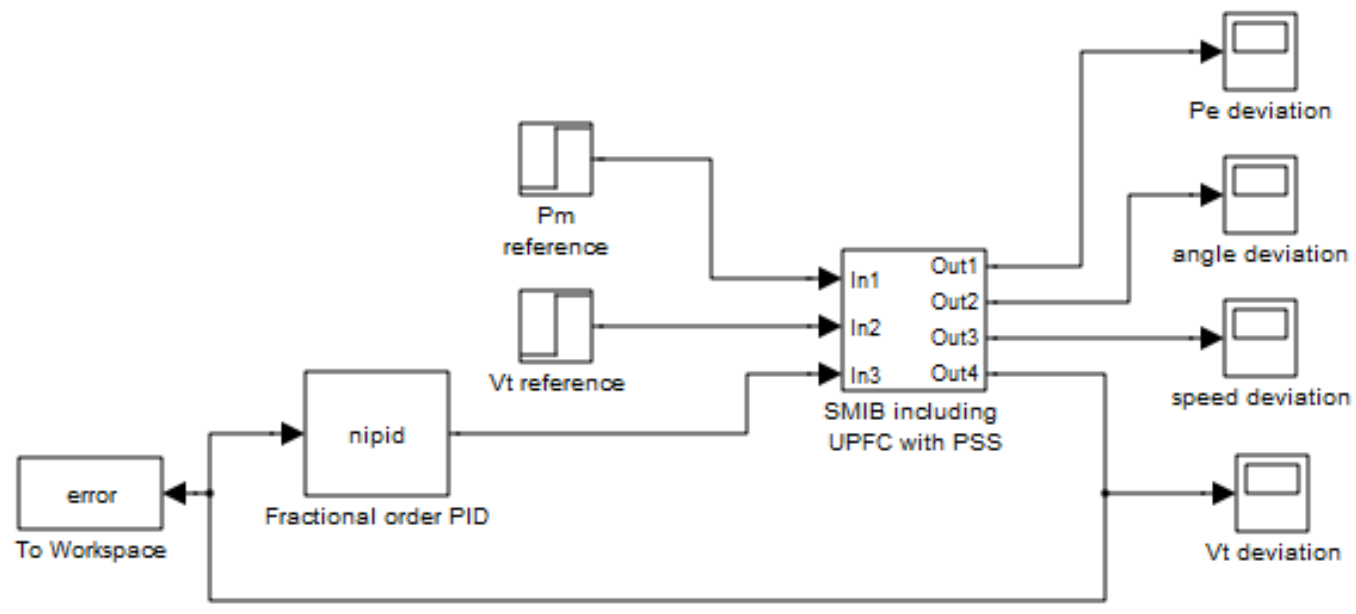

Fig. 7 SMIB power system controller model

Case1: 10\% Step increase in the mechanical input power

After running the Matlab Simulink model in Fig. 7, the optimal parameters of the controllers are listed in Table 2 under nominal operating condition. The response without pid (SMIB including UPFC with PSS) is shown with blue solid line with legend "without pid". It is clear from Fig.8 that without pid the power system oscillations are damped but with pid are effectively damped. It can be concluded from Fig.8 that the fopid controller has better performance than pid controller and also the terminal voltage deviation and rotor angle deviation performance are best in the design of Mfopid using Multi-objective optimization.

Table 2 Optimal parameters for the controller gains

\begin{tabular}{|c|c|c|c|c|c|}
\hline Controller Structure & $\mathbf{K}_{\mathbf{P}}$ & $\mathbf{K}_{\mathbf{I}}$ & $\mathbf{K}_{\mathbf{D}}$ & $\boldsymbol{\lambda}$ & $\boldsymbol{\mu}$ \\
\hline Mfopid & 26.280 & 15.061 & 0.405 & 0.939 & 0.859 \\
\hline Fopid & 15.208 & 9.983 & 0.240 & 0.889 & 0.709 \\
\hline Pid & 36.535 & 8.833 & 0.3879 & 1 & 1 \\
\hline
\end{tabular}
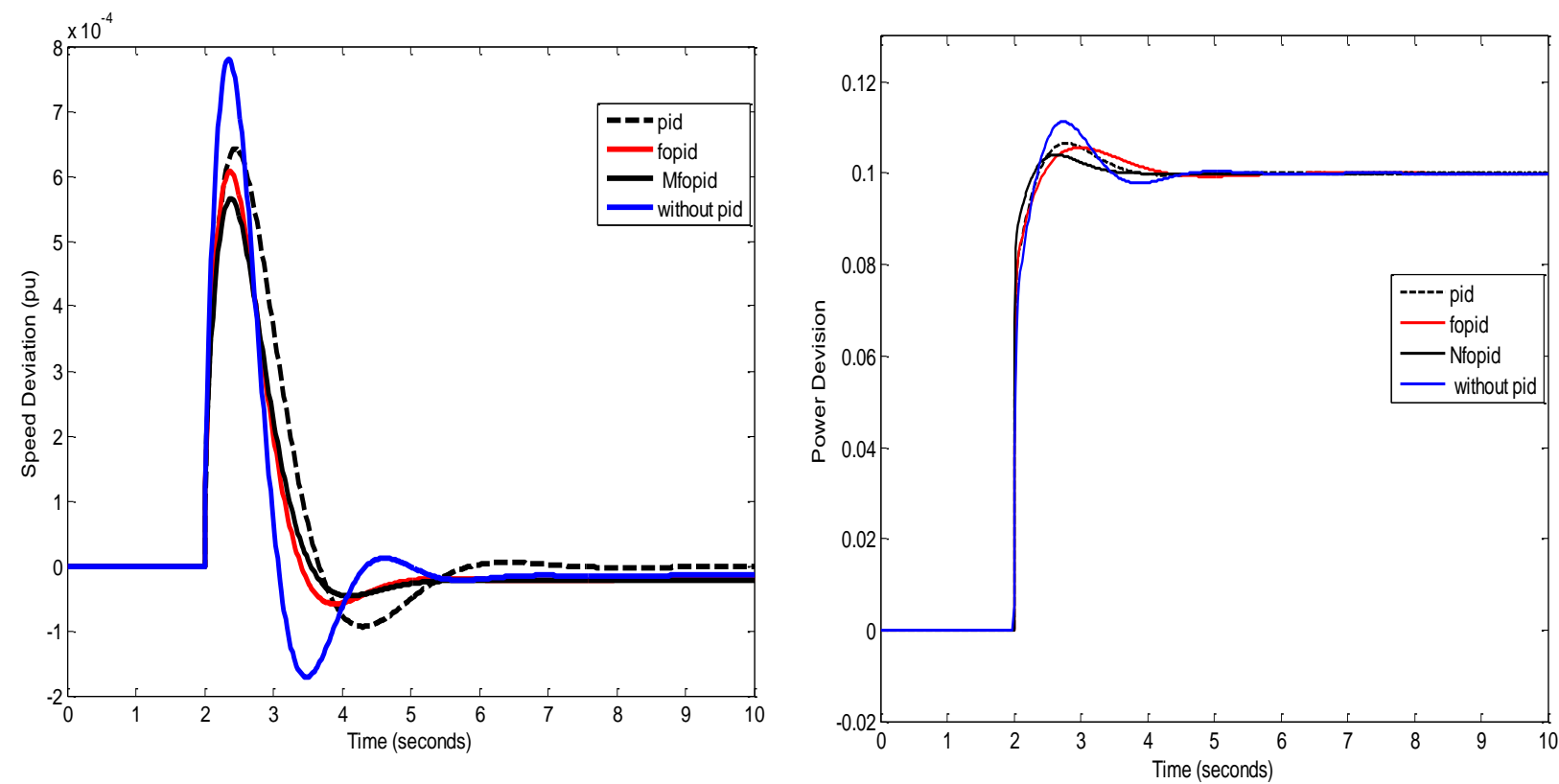

(a) Speed deviation response

(b) Electrical power deviation response 


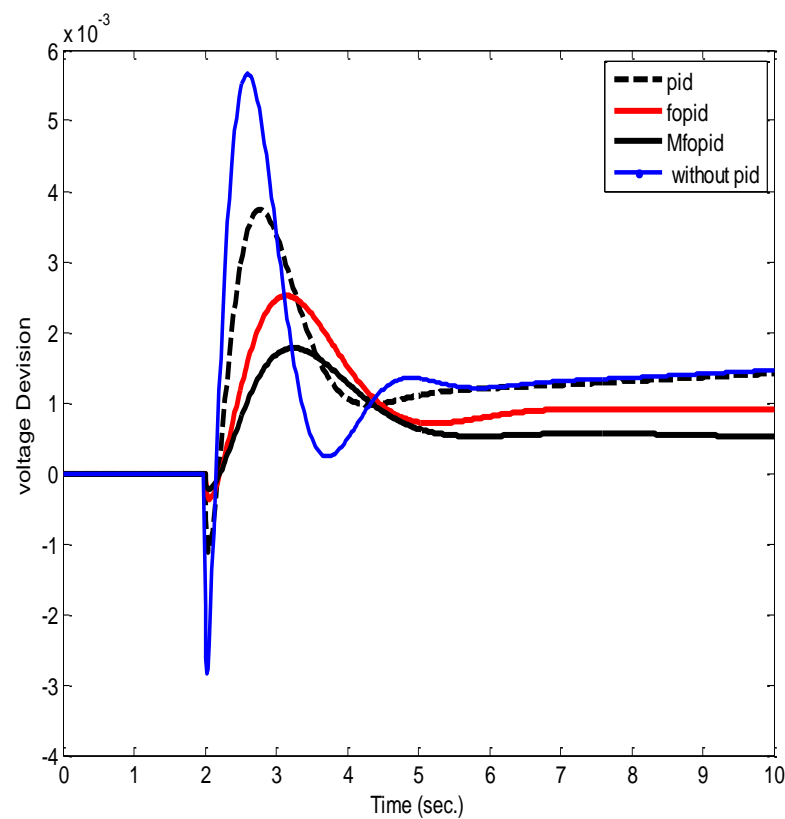

(c) Terminal voltage deviation response

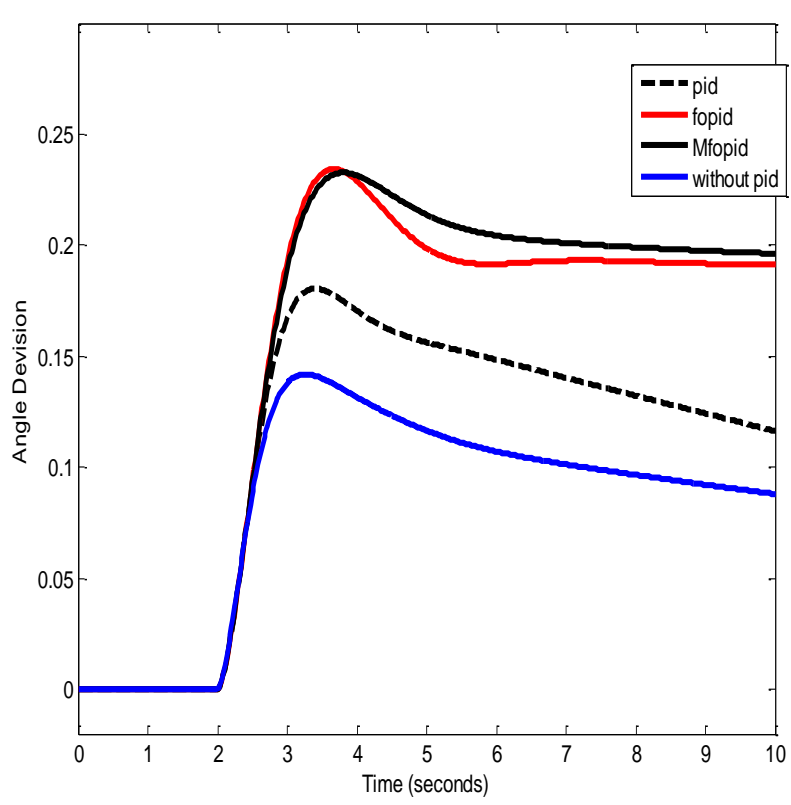

(d) Rotor angle deviation response

Fig.8 Dynamic responses for a $10 \%$ p.u. step change in $\Delta P_{m}$

\section{Case 2: $5 \%$ Step decrease in the mechanical input power}

To test the validity of the proposed approach, another disturbance is considered. The mechanical power is decreased by $5 \%$ at $\mathrm{t}=2.0$ and the system dynamic response is shown in Fig. 9. It can be observed from the system response shown in Fig. 9 that the performance of the system is better with Mfopid controller compared to the UPFC with fopid controller and pid controller. The oscillations in speed deviation and electrical power deviation are reduced and the steady-state error is minimized but the three controllers are slightly effect as shown in Fig.9.

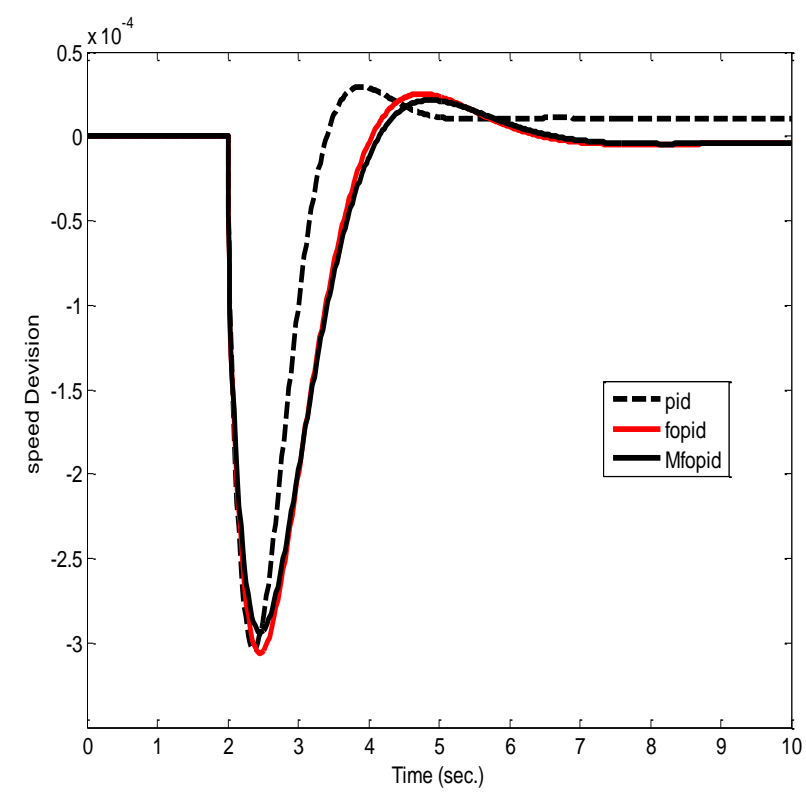

(b) Electrical power deviation response

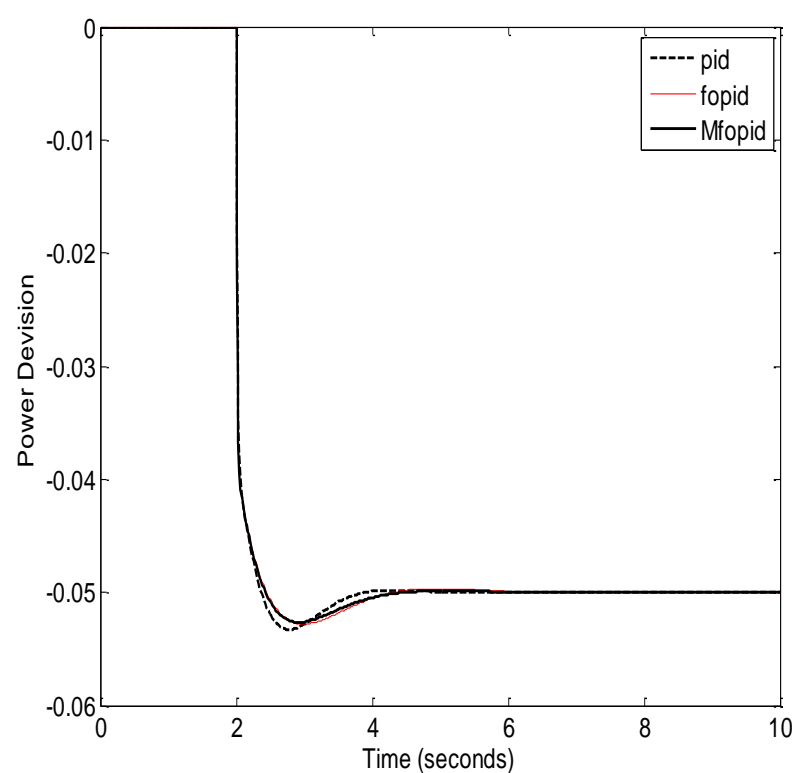

(a) Speed deviation response 


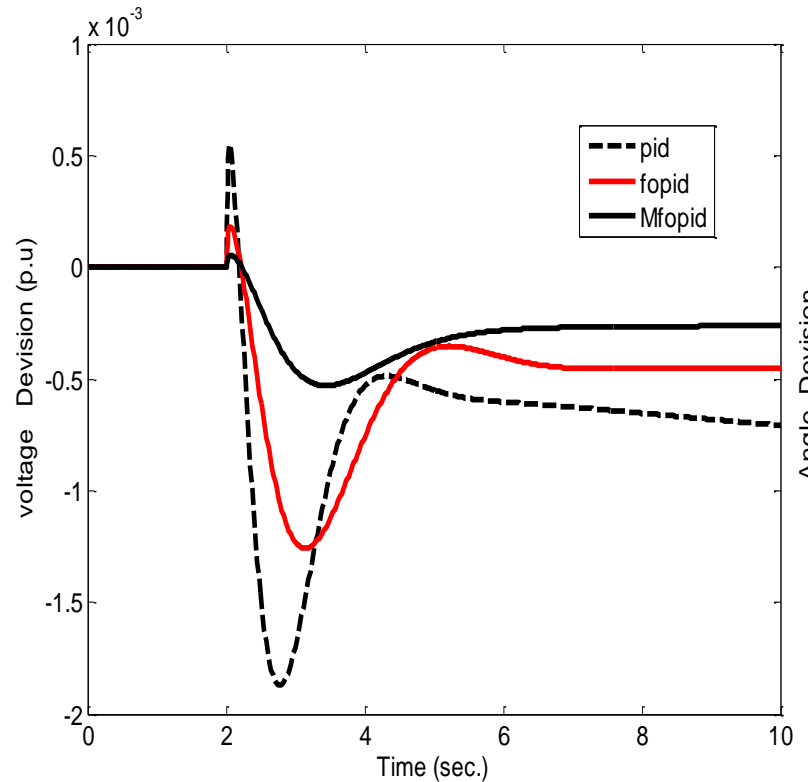

(c) Terminal voltage deviation response

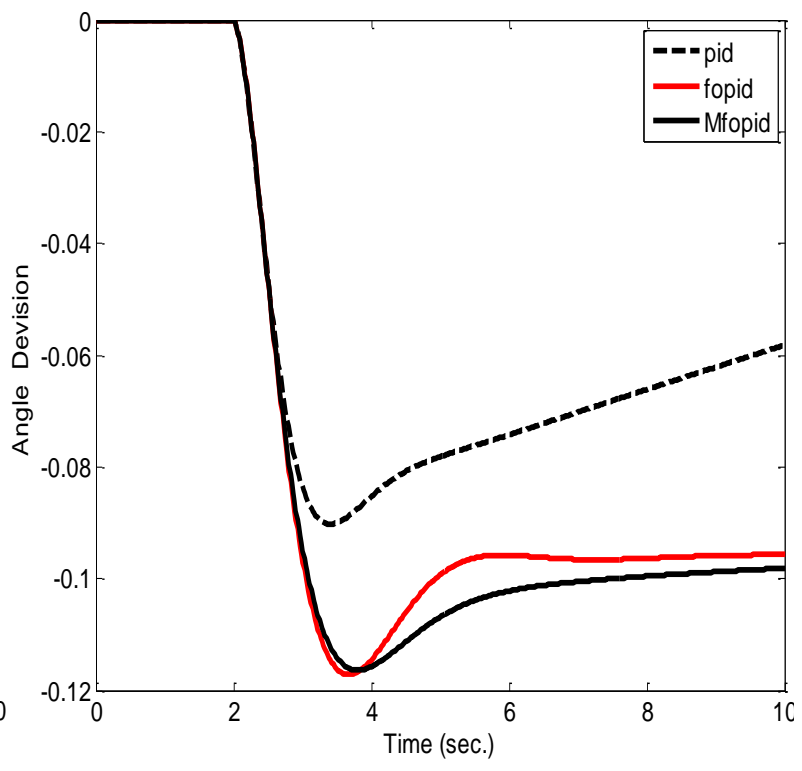

(d) Rotor angle deviation response

Fig.9 Dynamic responses for a $5 \%$ p.u. step decrease in $\Delta \mathbf{P}_{m}$

\section{Case 3: 10\% Step increase in reference voltage}

In this case, the reference voltage is increased by $10 \%$ at $\mathrm{t}=2.0$ and the system dynamic response is shown in Fig. 10. It can be concluded from Fig.10 that the UPFC with Mfopid controller gives better responses than UPFC with fopid and UPFC with pid .

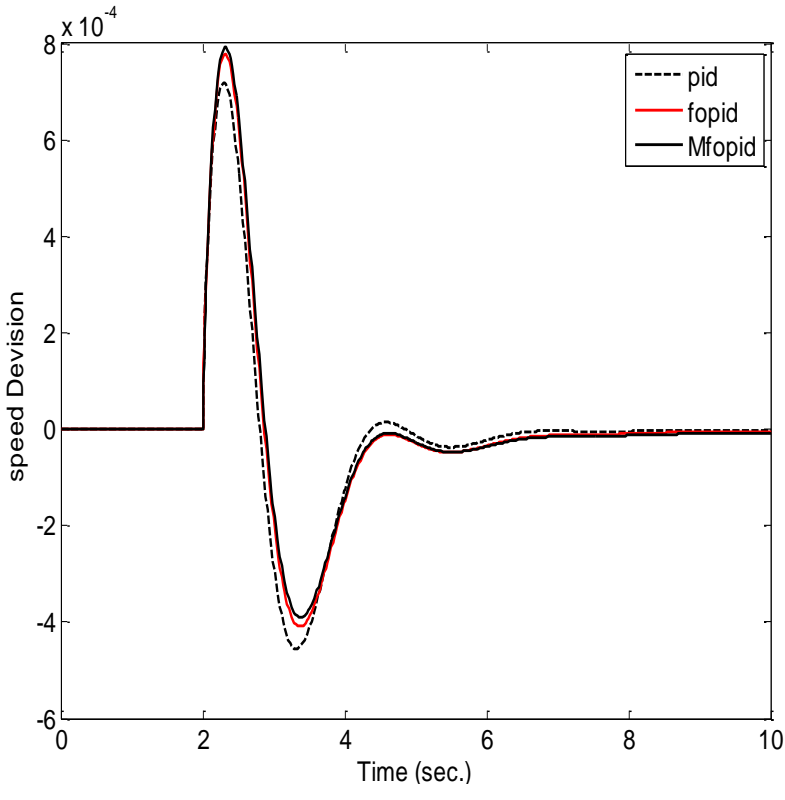

(a) Speed deviation response

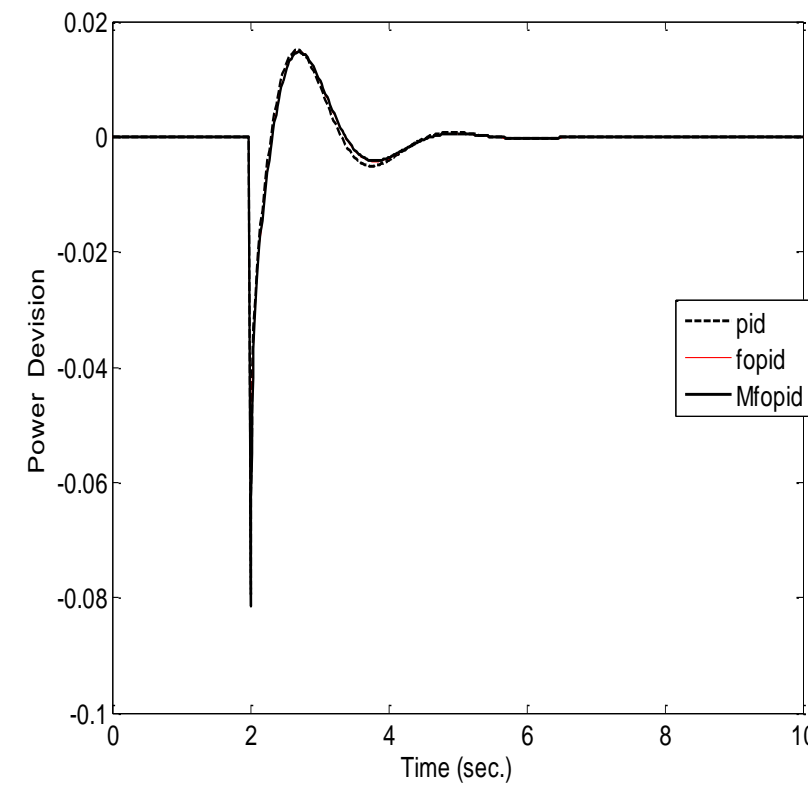

(b) Electrical power deviation response 


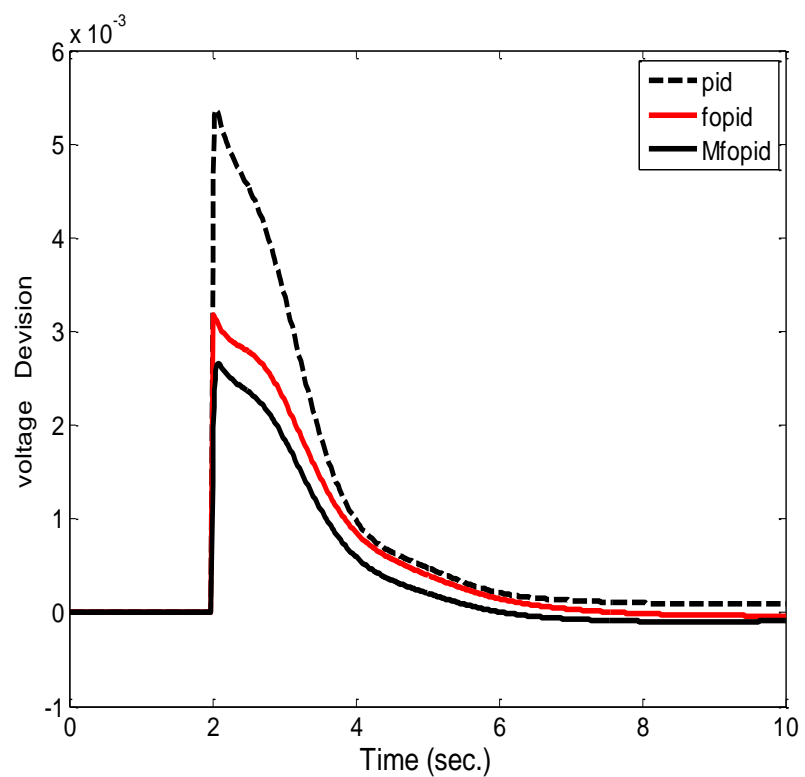

(c) Terminal voltage deviation response

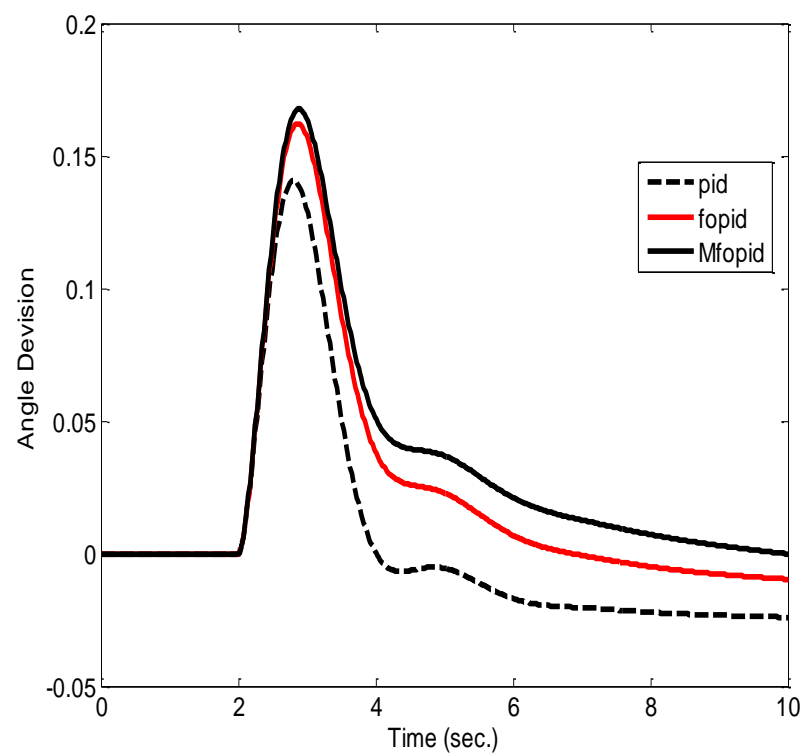

(d) Rotor angle deviation response

Fig.10 Dynamic responses for a $10 \%$ p.u. step change in $\Delta \mathrm{V}_{\text {ref }}$

\section{Case 4: Effect the variation of operating conditions (Heavy and Light):}

For nominal operating condition, the parameters of the controllers are presented in Table 2 and the $\mathrm{K}$ constants of the power system are given in Table 1 . The system response with heavy and light operating conditions for $10 \%$ step increase in the mechanical power as shown in Figs.11-12. It can be seen from figures that the UPFC with Mfopid controller achieves good robust performance and provides superior damping in comparison with the UPFC with fopid and UPFC with pid controller at all operating conditions.

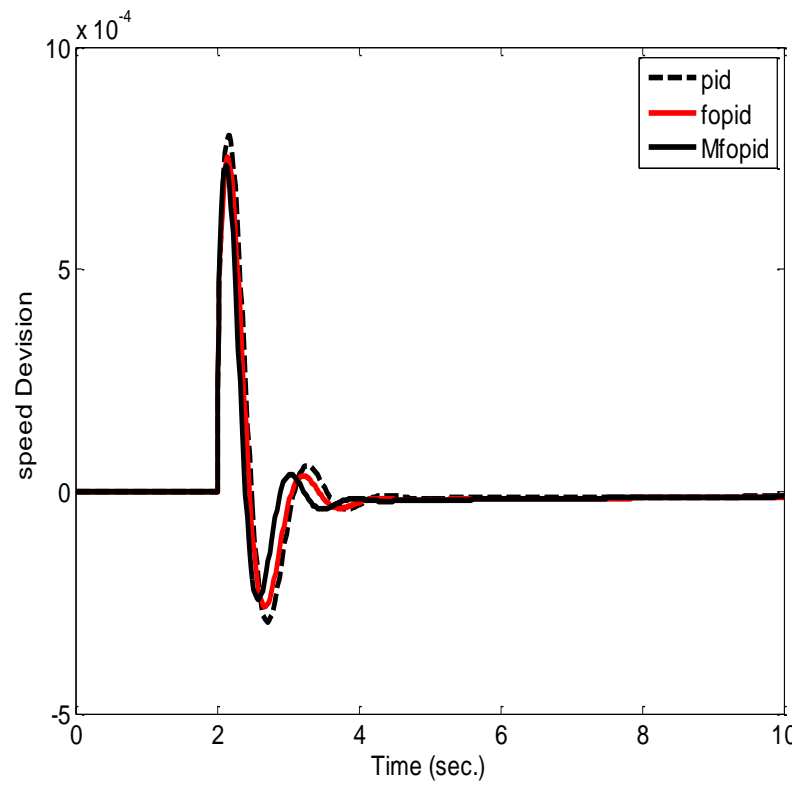

(a) Speed deviation response

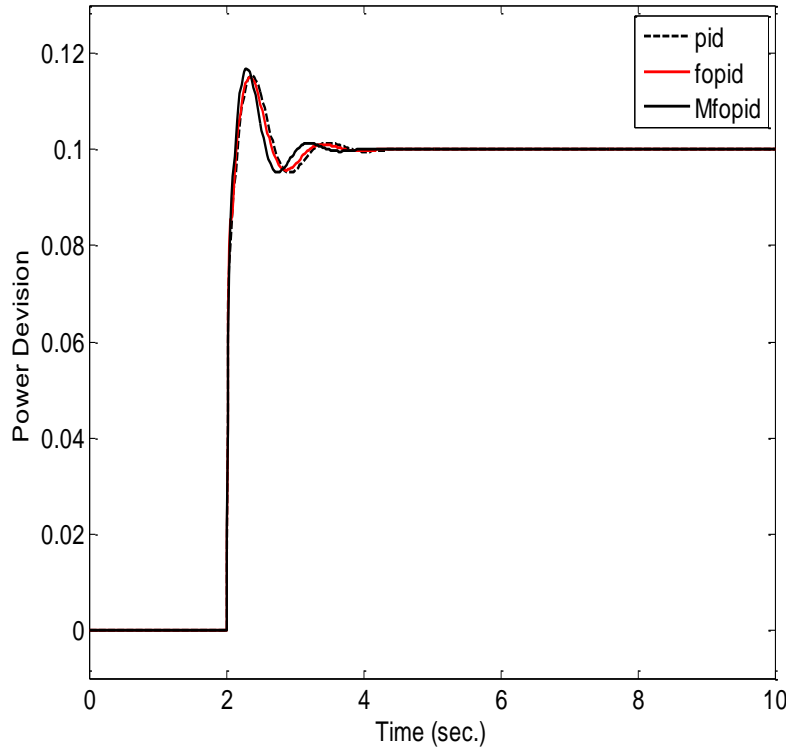

(b) Electrical power deviation response 

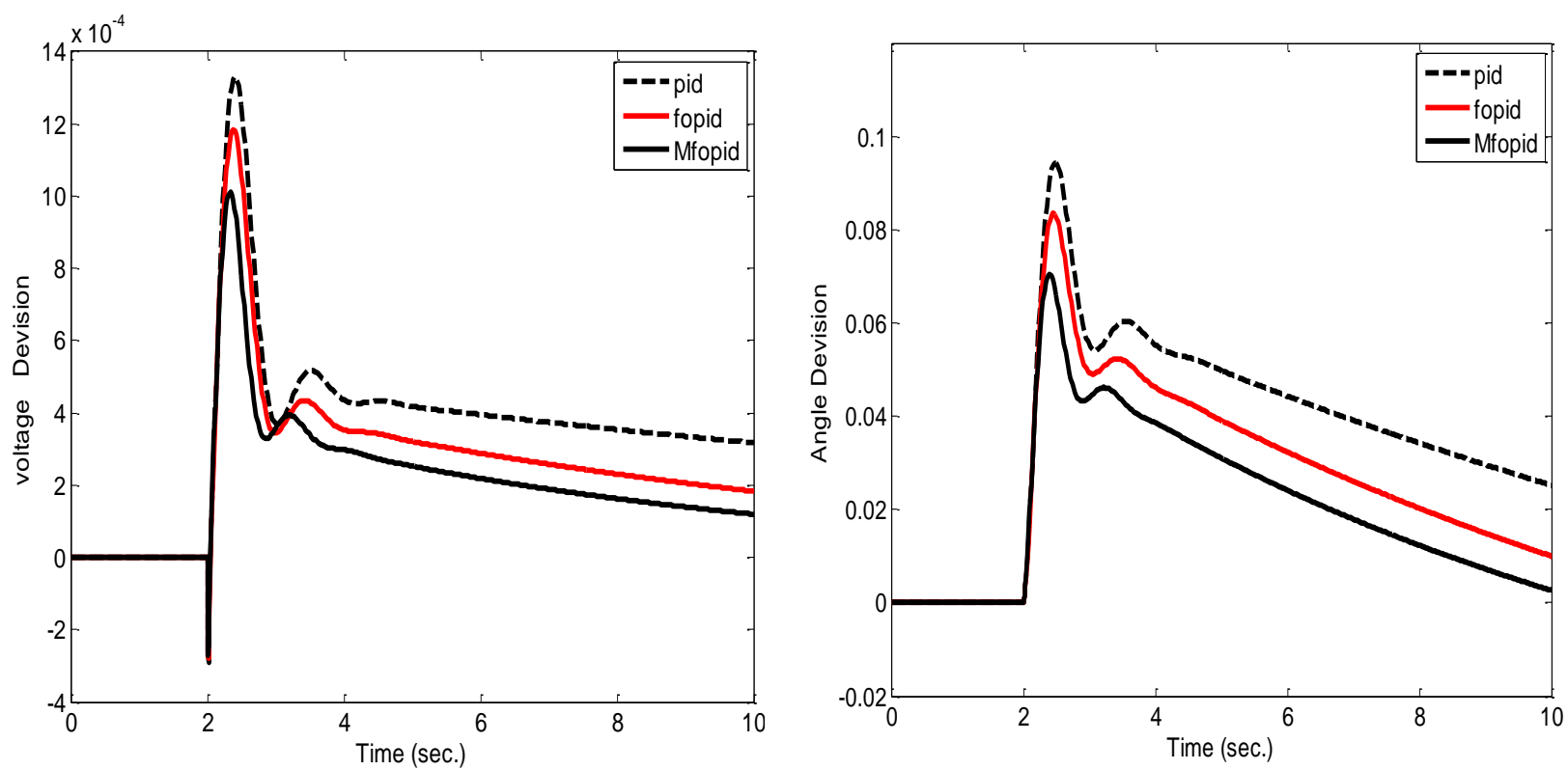

(c) Terminal voltage deviation response

(d) Rotor angle deviation response

Fig. 11 Dynamic responses at Heavy load operating condition

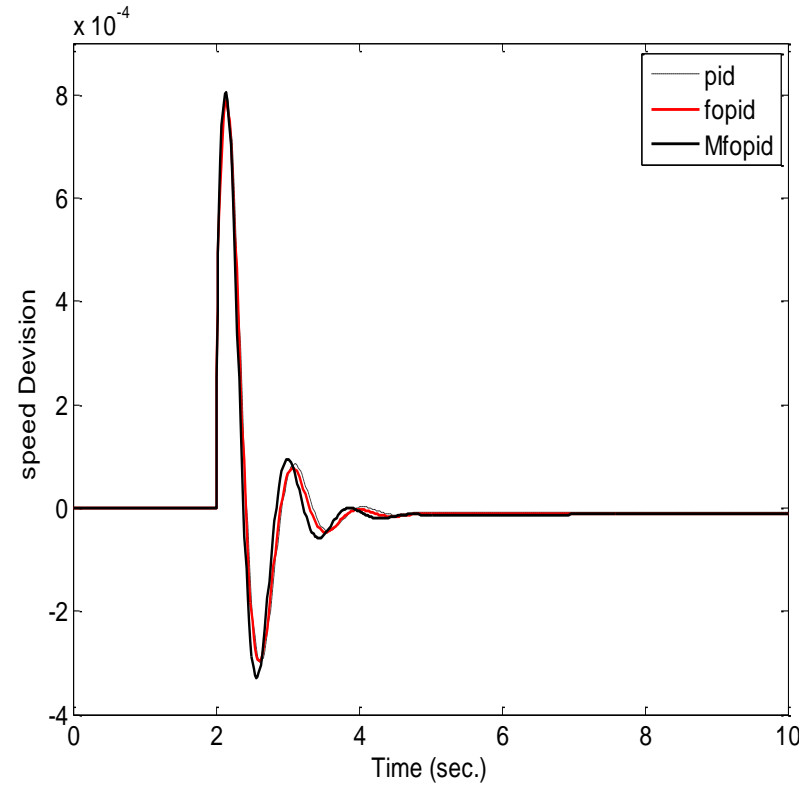

(a) Speed deviation response response

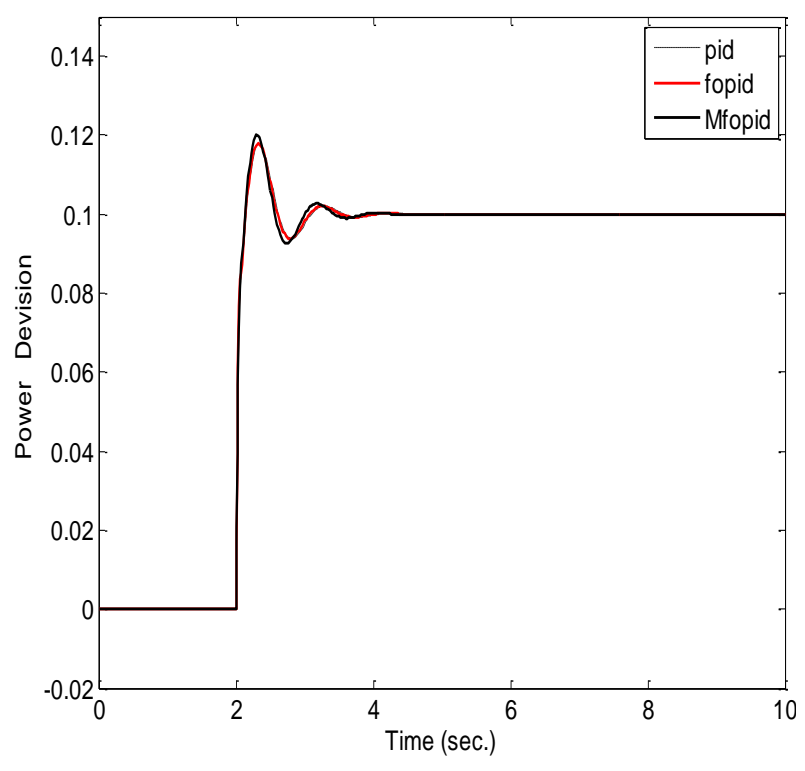

(b) Electrical power deviation 


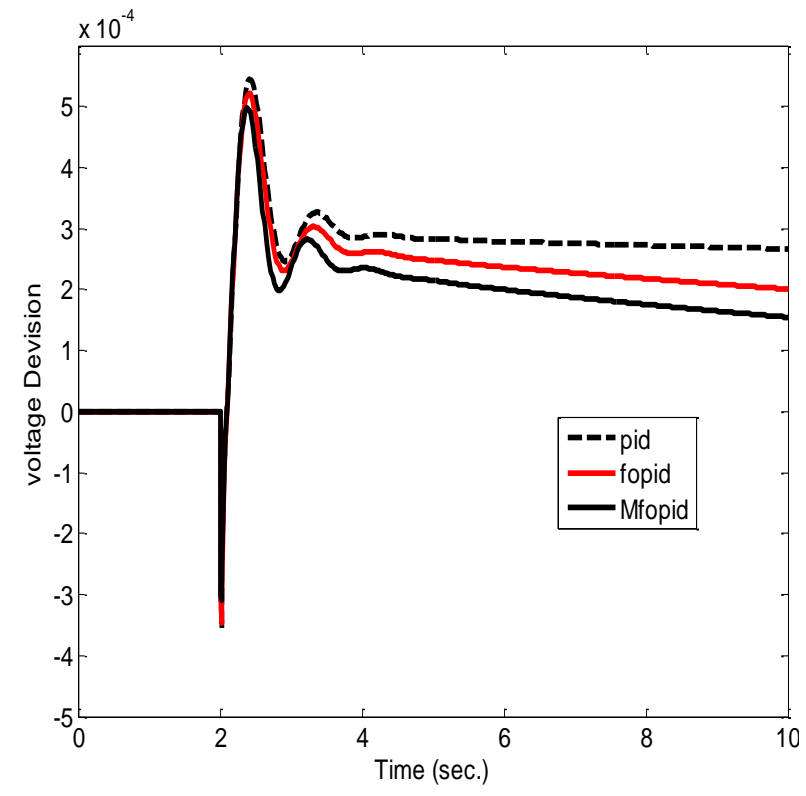

(c) Terminal voltage deviation response

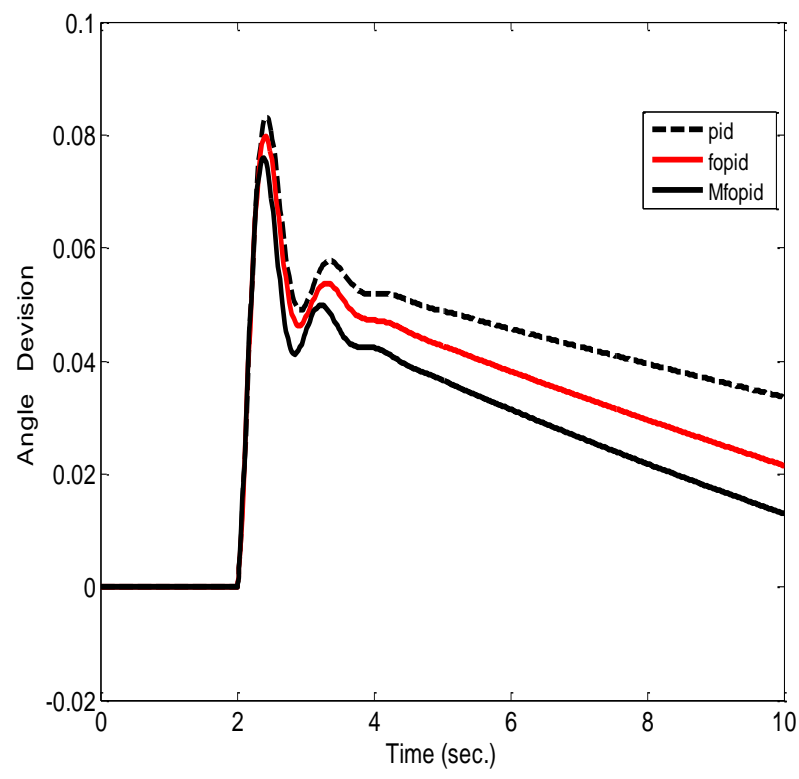

(d) Rotor angle deviation response

Fig.12 Dynamic responses for a $10 \%$ p.u. step change in $P_{m}$ Under Light Operating Condition

\section{Conclusion:}

In this study, the performance of UPFC based generator terminal voltage controller in SMIB power system is examined with three controllers i.e., pid, fopid, and Mfopid controllers. The design problem is transferred into an optimization problem and GA optimization technique is employed to search for the optimal UPFC-based controller parameters. Comparison between the responses of the pid, fopid, and Mfopid controllers has been investigated. The design of fopid controller can provide better results as compared with the pid controller. The simulation results show that the proposed Mfopid achieves good performance such as damping the frequency oscillations, overshoot, steady state error, raising time and settling time under various disturbances and wide range of operating conditions and is superior to other controllers. In near future, the project can be extended to multi machine model.

\section{Appendix}

The nominal parameters and the operating conditions of the SMIB system are given below (all value in pu):

Generator:

$$
\mathrm{H}=4, \mathrm{D}=0.0, \mathrm{~T}_{\mathrm{do}}=5.044 \mathrm{~s}, \mathrm{X}_{\mathrm{d}}=1.0, \mathrm{X}_{\mathrm{q}}=0.6, \mathrm{X}_{\mathrm{d}^{\prime}}=0.3
$$

Excitation System: $\quad \mathrm{T}_{\mathrm{a}}=0.01 \mathrm{~s}, \mathrm{~K}_{\mathrm{a}}=100$

Transformer: $\quad \mathrm{X}_{\mathrm{tE}}=0.1, \mathrm{X}_{\mathrm{E}}=0.1, \mathrm{X}_{\mathrm{B}}=0.1$,

Transmission Line: $\quad \mathrm{X}_{\mathrm{BV}}=0.3, \mathrm{X}_{\mathrm{e}}=0.5$

Operating Condition: $\quad \mathrm{P}=0.8, \mathrm{Q}=0.2, \mathrm{~V}_{\mathrm{t}}=1.0, \mathrm{f}=50 \mathrm{~Hz}$

UPFC Parameters: $\quad \mathrm{m}_{\mathrm{B}}=0.0789, \mathrm{~m}_{\mathrm{E}}=0.4013, \delta_{\mathrm{B}}=-78.2174^{\circ}, \delta_{\mathrm{E}}=-85.3478^{\circ}$

Parameters of DC link: $\mathrm{V}_{\mathrm{dc}}=2, \mathrm{C}_{\mathrm{dc}}=1$

\section{Reference:}

[1] L.Gyugyi, C.D.Schauder, S.L.Williams, T.R.Rietman, D.R.Torgerson, A.Edris, "The unified power flow controller: A new approach to power transmission control". IEEE Transactions on Power Delivery, Vol. 10, No.2, April 1995, pp. 1085-1097. 
[2] K.R.Padiyar, A.M.Kulkarni, "Control Design and simulation of United Power Flow", IEEE Trans. On Power Delivery, Vol.13, No. 4, October 1998, pp. 1384-1354.

[3] N.Tambey, and M.L.Kothari, "Damping of power system oscillation with UPFC", IEE Proc. C, Vol.150, March 2003, pp. 129-140.

[4] S.S.Tanwar, A. Khandelwal, S.Johri, "Analysis Of UPFC Based Damping Controller On A Single Machine Infinite Bus System (SMIB)", International Journal of Engineering Sciences \& Research Technology (IJESRT), ISSN: 2277-9655, Jun. 2012, pp.189-197.

[5] R.D.Saxena, K.D. Joshi., G.H.Raisoni, "Application of Unified Power Flow Controller (UPFC) for Damping Power System Oscillations - A Review", IJERT, Vol. 1 Issue 4, June 2012, ISSN: 2278-0181, pp.1-5.

[6] H.F.Wang, "Damping Function of UPFC", IEE Proc.-C, Vol. 146, Jan. 1999, pp.129140.

[7] A.Herreros, Baeyens, E., and Perán, J. R., "Design of PID-type controllers using multiobjective genetic algorithms,” ISA transactions, vol. 41, no. 4, 2002, pp. 457-472.

[8] Barbosa, R. S. , Tenreiro J. A., and Ferreira, I. M., "A Fractional Calculus Perspective of PID Tuning", In Proceedings of the DETC'03, Chicago, USA, September 2-6 2003, pp.1-9.

[9] I. Podlubny, "Fractional-order systems and $\mathrm{PI}^{\lambda} \mathrm{D}^{\mu}$ controllers", IEEE Trans. On Auto. Contr. vol. 44, no. 1, Jan. 1999, pp.208-214.

[10] I. Pan and S. Das, "Chaotic multi-objective optimization based design of fractional order $\mathrm{PI}^{\lambda} \mathrm{D}^{\mu}$ controller in AVR system," International Journal of Electrical Power and Energy Systems, vol. 43, no. 1, pp. 393-407, 2012.

[11] F. Ferreira and T. Machado, "Fractional-order hybrid control of robotic manipulators", in Proc. of the 11th International Conference on Advanced Robotics, Coimbra, June, 2003, pp.393-398.

[12] Rajinikanth Reddy.Mettu1, Ramesh.Ganta2,"Design of Fractional Order $\mathrm{PI}^{\lambda} \mathrm{D}^{\mu}$ Controller for Liquid Level Control of a Spherical Tank Modeled As a Fractional Order System", ISSN : 2248-9622, Vol. 3, Issue 6, pp.438-443, Nov-Dec 2013.

[13] Mohammad Reza Faieghi and Abbas Nemati, "On Fractional-Order PID Design", applications of MATLAB in Science and Engineering", Book Edited by Prof. Tadeusz Michalowski, pp. 237-292, Published: 09, September, 2011.

[14] S.S. Mohamed, A. E. Mansour, A.M. Abdel Ghany, "Adaptive Neuro-Genetic Control of a Unified Power Flow Controller in Electric Power System", Journal of Al-azhar University Engineering Sector JAUES, ISSN:1110-6409.

[15] Taher SA, Hematti R, Abdolalipor A., "Low frequency oscillation damping by UPFC with a robust Fuzzy supplementary controller", Int.J. Electr. Power Eng., 2: 314-320, 2008 .

[16] Al-Awami A, "A Particle-Swarm based approach of power system stability enhancement with UPFC", Electr. Power Energy Syst., 29:251-259, 2007.

[17] A.A.Eldamaty, S.O.Faried, S.Aboreshaid, "Damping power system oscillation using Fuzzy logic based Unified Power Flow Controller", IEEE Trans. On Electrical and Computer Engineering, May 2005, pp.1950-1953.

[18] Seyed Abbas Taher, Reza Hematti and Majid Nemati, "Comparison of Different Control Strategies in GA-Based Optimized UPFC Controller in Electric Power Systems", American Journal of Engineering and Applied Sciences, Vol.1, 2008, pp. 45-52. 
[19] Sidhartha Panda and Narayana Prasad Padhy, "MATLAB/SIMULINK Based Model of Single-Machine Infinite-Bus with TCSC for Stability Studies and Tuning Employing GA", World Academy of Science, Engineering and Technology 3, pp. 506-515, 2007.

[20] P.K.Dash, K.P. Basu, A.M.Sharaf, "UPFC controller design for power system stabilization with improved genetic algorithm", IEEE Trans. On Industrial Electronics Society, Vol. 2, Nov. 2003, pp.1540 - 1545.

[21] Duarte Pedro Mata de Oliveira Valério, "Ninteger v. 2.3 Fractional control toolbox for MatLab", 2005 / 08 / 17 . 